\title{
Developing a multidisciplinary process view on IFC standardization
}

\author{
M.Laakso \\ Information Systems Science, Hanken School of Economics, Helsinki, Finland
}

ABSTRACT: The industry foundation classes (IFC) file format is one of the most complex and ambitious IT standardization projects currently being undertaken in any industry, focusing on the development of an open and neutral standard for exchanging building model data. Scientific literature related to the IFC standard has dominantly been technical so far; research looking at the IFC standard from an industry standardization perspective could offer valuable new knowledge for both theory and practice. This paper proposes the use of IT standardization and IT adoption theories, supported by studies done within construction IT, to lay a theoretical foundation for further empirical analysis of the standardization process of the IFC file format.

KEYWORDS: standardization, standard, interoperability, IFC, BIM

\section{INTRODUCTION}

IT standards enable the seamless use of information technology, constituting the most basic building block for electronic communication. Network protocols, file formats, and hardware interfaces are not something most end-users have to concern themselves about for doing everyday computing tasks. However, the road traversed for a technology to become a well-established standard, is not always smooth. Standards are often the end-result of a lengthy process referred to as standardization. IT standards can in the most basic way be seen from the perspective of change-agents, functioning as mediators between change and stagnation in the industry (Cargill, 1989). Network effects heavily influence the IT standards landscape. The market is very prone to cluster around certain technological alternatives. This phenomenon has to do with IT adoption, a part of the IT literature that looks into factors that have to do with adoption decision-making on the level of the individual user or organization.

For the construction industry, IT standards have always been particularly important. With several organizations collaborating intensively in temporary project constellations, having compatible electronic assets within the project has always been of critical importance. Neutral standards for product models have been in development and use beginning with simple 2D and 3D computer-aided designs (CAD) in the 1970s, with the IGES standard being a good example of an open standard that is still used in many industries for visual modeling (Gielingh, 2008). However, a new approach to building modeling has evolved within recent years, offering the possibility to go beyond basic visual representations. This new technology is commonly referred to as building information modeling, or BIM for short.

The advanced features that BIM software offers have contributed to a considerable shift to the way IT is used in the construction industry. The exchange of BIM files is currently dominated by proprietary solutions, meaning projects must see to it that all collaborators have compatible software from the same vendor. An open file format has been developed to serve the market with an open standard, the IFC, which has been in active development for over ten years (iai-international.org). However, the actual IFC project makes up only a small part of all actual time and effort put into standardization work required to make the standard what it is today. The technical foundations of the IFC standard reach back to standardization work done on open geometrical standards for multiple industries. Work began in 1984 within the ISO 10303 project, which is more commonly known as the STEP project. (iaiinternational.org; Gielingh, 2008). So far IFC has not gained larger scale industry uptake outside indi- 
vidual pilot projects (Kiviniemi, Tarandi, Karlshøj, Bell, Karud, 2008), which is one of the primary motivators for the analysis in this paper.

This paper is the first step towards finding an answer to the following questions: What factors influence the IFC standardization process and how do these factors affect its progress? By finding out answers to these important questions we could gain a better understanding of important circumstances related both to the development of the standard itself as well as aspects that are related to its adoption in the industry.

Since the research questions span the boundaries of multiple bodies of research, a multi-disciplinary approach minimizes the need to 'reinvent the wheel', and enables a sharp focus on issues relevant to the analysis of IFC standardization. Consequently, research from the construction IT domain is used to provide the necessary industrial context, and technical information, while the well-established IT standardization and IT adoption literature is drawn upon to provide theory, typology, and contribute to the analytical lens. Utilizing these research streams in parallel is for the most part unproblematic as they share the same functionally oriented research paradigm.

The paper is structured as follows: In the first section we take a look at BIM \& IFC technologies as well as look at how they relate to prior research within construction IT. Next up is a review of relevant IT standardization literature and applying IFC into that context. This is followed by a similar, albeit briefer, approach to IT adoption research. Last is a discussion section with concluding remarks and suggestions for further research.

\section{BIM \& IFC - PUTTING THINGS INTO PERSPECTIVE}

Incompatibility leads to redundancy and inefficiency, which in turn costs building owners money. The United States National Institute of Standards estimated on the basis of a comprehensive multimethod study that insufficient interoperability in information technology tools costs the US capital facilities industry, $\$ 15.8$ billion USD annually, based on data from 2002 (Gallaher, O'Connor, Dettbarn, Gilday, 2004). Capital facilities include commercial, industrial and institutional buildings. The majority of the sum, which equates to $1-2 \%$ of the whole US capital facilities industry annually, was identified as originating from redundant data entry, redundant IT systems and IT staff, inefficient business processes, and delays indirectly caused by these inefficiencies. The study puts standardization within the industry into perspective, and clearly shows that there are considerable monetary gains to be had by increasing compatibility between information systems.

\subsection{IFC - Who, when and why?}

When the IFC project was initiated in 1995, work on the standard was not started from scratch, in fact far from it. The IFC standard is built upon universal geometric definitions from previous standardization projects, most notably ISO 10303, which is better known as STEP (Standard for the Exchange of Product model data) (iai-international.org). The ambitious STEP project was started in 1984 with a mission to develop open computer modeling standards for multiple manufacturing industries, and the project is still actively in progress. One reason for branching out IFC as an industry consortium from the STEP development was that the standardization process was considered too slow and unresponsive to meet market demand for the construction industry (Tolman, 1999). The IFC standard is in the process of becoming an official international standard of its own, under the label of ISO16739 (iso.org). However, history has shown that acknowledgement by an official standards body does not on its own make or break proliferation of a technology in the industry. Many formal standards have faded away during the standardization process; aligning 'time-to-standard' with 'time-to-market' goals is of great importance. (Gielingh, 2008).

BuildingSMART is the international non-profit organization administrating the industry consortia responsible for IFC standardization. The organization was formerly known as The International Alliance of Interoperability (IAI). BuildingSMART has 13 regional alliances around the world, all of them represented by two delegates in an international council that meets twice a year to coordinate business and technical strategy. In the event of a vote, each regional alliance is equal to one vote. The International Technical Committee is responsible for highlevel decision-making and technical project management within buildingSMART. The Technical Committee reports straight to the International Council. (buildingSMART.com ${ }^{\mathrm{a}}$ ) There have been several major and minor revisions to the IFC standard along its development, with the most recent implementable version being IFC2x3. So far the versions have been published with quite high variance 
in timeframes, some within a year of the previous release and others with 3 years of development time (iai-tech.org).

For software to get accredited an official IFC certification by buildingSMART it has to go through a two-stage process. In the first stage the software is tested with a set of synthetic test files during a public certification workshop. As a second stage, after end-users have had at least 6 months to judge that the IFC-interface is of high enough quality, another public certification workshop is arranged where real project data is used (buildingSMART.com ${ }^{\mathrm{a}}$ ). Aspects of the certification process have been debated in the literature (Kiviniemi et. al, 2008; Amor, Jiang, Chen, 2007). Criticism has mostly been based on arguments that IFC certified software is not working as could be expected, creating errors in building models even with relatively simple data exchanges.

\section{IT STANDARDIZATION}

Standardization in the context of IT emerged as a clearly separate scientific field towards the end of the 1980s. Prior to that point there had been mostly descriptive case studies that did not really offer much in the way of theoretical advancement (Cargill, 1989). The demand for standards has steadily grown as computing has moved away from the isolated workstations of the past to networked personal computers with increased potential for communication and collaboration.

The term 'standard' has been thrown around with slightly different meanings in the past, however, initiatives towards a common typology have been presented (Cargill, 1989; de Vries, 2005) to reduce ambiguity of constructs and strengthen the communication within the research stream. The following definition is used throughout this paper to support this notion:

"A standard is an approved specification of a limited set of solutions to actual or potential matching problems, prepared for the benefits of the party or parties involved, balancing their needs, and intended and expected to be used repeatedly or continuously, during a certain period, by a substantial number of the parties for whom they are meant." (de Vries, 2005, p. 15)

'Standardization' is defined as the activity of creating a 'standard', which by definition is not limited of any number or type of tasks. In many instances suc- cessful IT standardization is a continuous process in many branches of modern business and it is not always easy to define the point in time when standardization ends.

To narrow down the nature of IFC standardization in accordance to the common standardization typology presented in de Vries (2005), the following details are worthwhile to define:

\section{- Open, formal, international, consortium stan- dard}

The standardization process is handled by a global alliance of companies and organizations, administered by buildingSMART. Both the full IFC standard specification and information about standardization developments are available on the web, free for anyone to view, comment on, and implement.

\section{- Indirect horizontal compatibility standard}

IFC is a file format that serves as a compatibility bridge between BIM applications from different vendors. BIM applications still retain their own native file formats and internal structures so compatibility is achieved indirectly by the use of IFC.

\section{- Designing standardization}

It is not simply a matter of selecting and agreeing on features from existing alternatives, even though the project started out that way with STEP definitions as a base. The technical solutions have to be formally designed and created as part of the standardization process.

\section{- Anticipatory standardization}

In 1996, when the International Alliance for Interoperability was formed, IFC could be classified as an anticipatory standard; meaning that development of the standard was initiated in anticipation of future demand for compatibility. BIM technology, as we know it today, was very much in its infancy back then and the aim was to develop a neutral standard before proprietary solutions take over the market. However, observing the situation in the year 2009 and the standardization work could now be labeled as concurrent with the development of BIM technology.

Generalizing results from earlier standardization studies on individual core functions that BIM aggregate, like $\mathrm{CAD}$ and $\mathrm{B} 2 \mathrm{~B}$ communication technologies, is one possible way of starting the journey into uncharted waters. However, generalizations of that 
kind do not come without their own set of strings attached.

In this vein, IFC could then be seen from the perspective of a standard for electronic B2B communication in the construction industry; this enables parallels to be drawn to earlier research regarding standards of that kind, like EDI and XML-based equivalent standards (e.g. Clark, Atkin, Betts, Smith, 1999: Tolman, Böhms, Lima, van Rees, Fleuren, Stephens, 2001). However, the IFC standard is much more complex than the $\mathrm{B} 2 \mathrm{~B}$ standards that have been developed before it. IFC is a modular way to integrate supply-chains between designers, builders, and fabricators simply by extracting information from the complex building model containing all relevant information. What also makes this standardization effort different is the setting of the construction industry, where business contracts between companies involved in projects typically are shortterm. There is less incentive to invest time and money to set up customized electronic interfaces between temporary stakeholders. There have been studies looking into relatively simple standards for electronic procurement, like EDI, which support this reasoning (Premkumar \& Ramamurthy, 1995). As materials calculation and procurement information are features supported by IFC, the parallels to existing standards built solely for that purpose are not too disconnected from their context if one acknowledges the limitations with the approach.

There have been studies looking into the standardization of open standards for CAD from different perspectives (e.g. Howard \& Björk 2007; Gielingh, 2008). However, direct comparisons to findings related to traditional CAD standardization should also be made with caution as IFC has a much wider scope, both in the number of involved stakeholders and level of technical complexity. As briefly mentioned earlier, the IFC format does not only have the specifications about visual data, it also enables the use of a rich set of metadata tied to the modeled objects which potentially make several stages of the construction process more efficient. Based on the metadata, calculations like scheduling, cost estimates, and energy consumption can be performed. The BIM model stored in IFC format is to be used during the whole lifecycle of the building, not just by architects and a few select stakeholders during the design and build stages, like CAD drawings have been traditionally used.

The possibility to use applicable results from previous studies where possible is of course always en- couraged within science, however, one must acknowledge the fact that BIM is a much more monolithic system than anything before it in the industry, which should caution against going to far with deductive conclusions based on individual parts of the system made in legacy environments.

\subsection{The lifecycle of standards}

To develop a process-based theoretical framework for IFC standardization with a strong theoretical foundation there is definitely a need to look at generic IT standardization process-models from existing research. When IT standards started to gain increased scientific interest during the 1980s, the first process descriptions were linear in structure (Cargill, 1989). However, more recent studies looking at standardization have noted that reality does not always follow this linear formula (e.g. Fomin, Keil, Lyytinen, 2003; Cargill, 1995). It would seem that particularly technically complex standards and anticipatory standards benefit from an iterative approach. Like in any healthy developing research stream there are now several theoretical proposals for standardization lifecycles. Rather than selecting just one model, which would be based on the results of a single study, a more generic approach is made possible with the help of a recent literature review. Söderström (2004) reviewed seven published IT standard lifecycle models and discovered a lot of common ground amongst the models. The reviewed models also complemented each other well; most of the omissions and differences had to do with different perspectives on when standardization begins and ends and which activities to include as part of the standardization process. The generalized model, without extensions, can be seen in Figure 1.

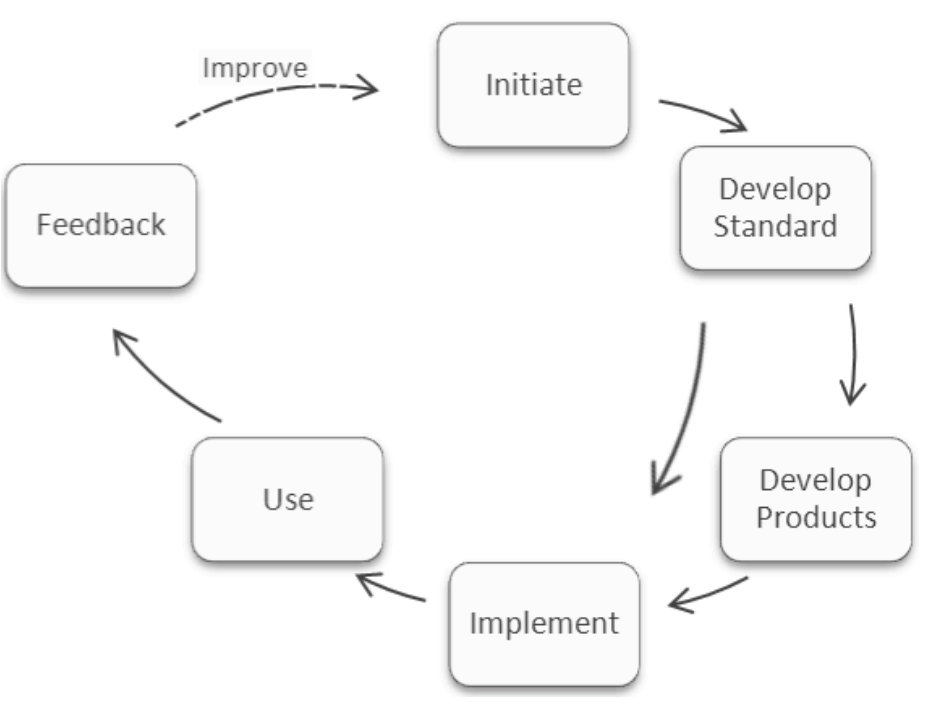

Figure 1 - Generalized standards lifecycle (Söderström, 2004) 
The model depicts six main stages that together comprise standardization. Initiation, the first stage, is identified by the need for the standard emerging and being acknowledged. The next stage, develop standard, is where the standard is explicitly defined and developed. Then, depending on the standard at hand, what follows is either development of products incorporating the standard or a jump straight to implementation. The implementation stage is identified by organizations applying the standard into their own environment. Next up is the use stage, which means that the standard is actually used in its intended environment. Feedback, a stage mentioned only in de Vries (2002) lifecycle among the reviewed models, is the stage where users of the standard submit feedback for further improvement of the standard.

Looking at the IFC standard from the perspective of the lifecycle model makes the complex standardization process easier to segment for analysis. Initiation is easy to pinpoint as the history of the IFC standard is relatively well documented. In August 1994, 12 US based companies joined together examining the possibility of developing an open standard for increased compatibility in emerging building information modeling software, driven mainly by economic motivations (iai-international.org). Development of the standard started soon after that, with the original consortia opening up the doors for other interested software vendors and construction industry stakeholders around the globe. Using definition material from existing open CAD file formats, from within the ISO STEP standard, technical development did not have to be started from scratch, and the first version of the IFC standard was published in January 1997 (iai-international.org). Implementation in BIM software did not happen until July 1998, with several commercial modeling suites supporting IFC 1.5.1 (iai-international.org). Use in actual projects is so far weak, even though many commercial BIM suites have been IFC certified since 2002; 13 applications at that time supported IFC 2.0 (iaiinternational.org). Feedback function is very much an integral part of the evolution of the standard. New versions, both major and minor, have been published at several occasions. The need for predictable release cycles for the IFC version releases was recently acknowledged as an important factor for improving industry uptake of the standard (Kiviniemi et. al 2008), which in turn depends heavily on receiving feedback from testers and implementers. Here the scientific community can make a big contribution to the development of the standard. The many technical research papers evaluating IFC use in pilot studies have certainly been taken as constructive feedback to the developers of the standard when planning future versions.

\section{IT ADOPTION}

Research focusing on aspects of IT adoption is partly overlapping with that of IT standardization research, the main reason being that standards compliance is a key influence on adoption decisions because standards enable the existence of network effects (Hall, Khan, 2003 p. 6). While the standardization literature only looks at the process of standardization, the IT adoption literature should be considered a natural continuation of the same process, seen from the perspective of organizations or individuals, depending on the chosen unit of analysis. In this paper focus is on the organizational and group level; the perspective or opinion of individual users is not focused on at this stage. To improve our understanding of adoption criteria, which play an important role in creating actual industry demand for standardization, each stakeholder group should be studied individually. However, that is beyond the scope of this paper and something that requires a thorough empirical study with recent data.

Going by information gathered so far, it would seem that construction industry professionals using BIM software are not primarily concerned with supporting ideologies of open standards when doing their work, especially if that means accepting technical deficiencies as a result. In a recent web-survey probing industry professionals for criteria when choosing BIM software "Full support for producing construction documents so that another drafting application need not be used" was ranked in $1^{\text {st }}$ place while "IFC compatibility" came in at spot 16 (Khemlani, 2007). These results would suggest that the benefits of supporting IFC were not perceived as valuable enough, at the time of the survey, to sway away from dominating proprietary solutions and their full intracompatibility. The results of this individual survey are perhaps not to be looked into too much when drawing broad theoretical conclusions, however, it can be considered to at least give an estimation of the general climate among industry professionals.

\section{DISCUSSION \& CONCLUSIONS}

So far the scientific interest for BIM outside of architecture, engineering, and construction disciplines 
has remained low, even though the technology brings with it so much more than just a new way to draw buildings. The low interest and involvement from the main IT research disciplines might be due to the building modelling domain knowledge involved which might act as a threshold for a wider scientific discussion. If once again contrasting to ERP, which has long been one of the more active areas of IT integration research, the difference between the two information systems becomes clearer.

BIM technology has gained strong governmental support in many countries, public sector demand for IFC compliant BIM has been credited to be pushing the technology forward in many reports (Kiviniemi et. al, 2008; Succar, 2009; Eastman et. al, 2008). For example, public sector construction projects in the United States, Singapore, Norway, Finland and Denmark are all to variable extents required to use and deliver BIM models at different stages of the project. Some countries are even specifically requiring IFC models, a factor which is certainly an accelerator for the standardization (Kiviniemi et. al., 2008). As very important customers for builders, public sector construction organizations have the necessary bargaining power to dictate the requirements. Being an early-adopter of a standard is a considerable investment for companies, both operationally and financially, and incentives have to be there to make it viable. If buyers do not require open standards compliance one should not expect providers to invest in it, they will most likely only sell what there is actual demand for (Cargill, 1989)

Maintaining momentum is critical to keep the standardization process in constant movement, and "time-to-market" is certainly an important aspect to place emphasis on in standardization. Even though the IFC standard has endured a long standardization process, and still has some way left to go, its momentum shows few signs of slowing down. On the contrary, there have recently been developments and commitments made by important industry actors (e.g. tekla,com - Tekla joins buildingSMART 16.2.2009; buildingSMART.com ${ }^{\text {b }}$ - two new German-speaking public bodies join buildingSMART 18.11.2008).

For the purpose of mapping and analyzing the factors affecting IFC standardization it would be important to identify the key stakeholders involved, both those acting within the standardization process, and those influencing through external or indirect means. How one goes about doing this exhaustively is one problematic aspect yet to be resolved. Because of the organizationally fragmented nature of construction work, enhancing collaboration among stakeholders will be increasingly relevant as IT is integrated and leveraged in future projects.

\section{REFERENCES}

Amor, R., Jiang, Y., and Chen, X. (2007) BIM in 2007 - are we there yet? Proceedings of CIB W78 conference on Bringing ITC knowledge to work, Maribor, Slovenia, 26-29 June, 159-162

buildingSMART ${ }^{\mathrm{a}}$ - Model - Industry Foundation Classes (IFC) http://www.buildingsmart.com/bim Accessed on 22.02.2009

buildingSMART ${ }^{\mathrm{b}}$ - Two important public bodies joint http://www.buildingsmart.com/buildingsmart_germanspeak ing_two_ministries_are_now_members Accessed on 22.02.2009

Cargill, C. (1989) Information Technology Standardization: Theory, Process, and Organizations, Digital Press, Bedford, MA

Cargill C. In: Kahin, B., Abbate, J. (Ed.) (1995) Standards Policy for Information Infrastructure. MIT Press, Cambridge, 79-99

Clark, A., Atkin, B., Betts, M., Smith, D. (1999) Benchmarking the Use of IT to Support Supplier Management in Construction, ITcon, Vol. 4, pg. 1-16, http://www.itcon.org/1999/1

de Vries, H. (2002), Standardisation education, ERIM report series: Research in Management, Ref no. ERS-2002-82ORG, Rotterdam, the Netherlands

de Vries, H. In: Jakobs, K. (Ed.)(2005) Advanced Topics in Information Technology Standards and Standardization Research Volume 1, Hershey, PA, USA, Idea Group Publishing, 11-36

Eastman, C., Teicholz, P., Sacks, R., and Liston, K. (2008). BIM Handbook: A Guide to Building Information Modeling for Owners, Managers, Designers, Engineers, and Contractors. John Wiley, New Jersey

Fomin V., Keil T., Lyytinen, K. (2003) Theorizing about Standardization: Integrating Fragments of Process Theory in Light of Telecommunication Standardization Wars," Case Western Reserve University, USA. Sprouts: Working Papers on Information Systems, 3 (10) Available at: http://sprouts.aisnet.org/3-10

Gallaher, M. P., O'Connor, A. C., Dettbarn, J. L. and Gilday, L. T. (2004) "Cost Analysis of Inadequate Interoperability in the U.S. Capital Facilities Industry", GCR 04-867, NIST

Gielingh, W. (2008) An assessment of the current state of product data technologies. Computer-Aided Design, Vol. 40, Issue 7, 750-759

Hall, B., Khan, B. (2003) Adoption of new technology, UC Berkeley Working Papers No. E03-330. Berkeley, CA, University of California Berkeley, Department of Economics, $1-20$

Howard R., Björk, B-C. (2007) Use of standards for CAD layers in building, Automation in Construction, Vol. 16, Issue 3, 290-297

IAI, A short history of the IAI and the IFC information Model (2000) http://www.iai-international.org/about/history.html (Accessed 10.4.2006)

IAI Tech International - Summary of IFC releases http://www.iai-tech.org/products/ifc_specification/ifcreleases (Accessed 18.3.2009)

ISO 16739 - Industry Foundation Classes, Release 2x, Platform Specification (IFC2x Platform)

http://www.iso.org/iso/iso_catalogue/catalogue_tc/catalogu e detail.htm?csnumber $=3 \overline{8} 056$ (Accessed 18.3. 2009 ) 
Jacobs, F.R., Weston, F.C. Jr., Enterprise resource planning (ERP) - A brief history, Journal of Operations Management Vol. 25, Issue 2, 357-363.

Khemlani, L. (2007), Top criteria for BIM solutions A survey conducted by AECbytes, http://www.aecbytes.co $\mathrm{m} /$ feature/2007/BIMSurveyReport.html Accessed on 22.02.2009

Kiviniemi, A., Tarandi, V., Karlshøj, J., Bell, H., Karud, O.J. (2008) Review of the Development and Implementation of IFC compatible BIM, Erabuild

NBIMS (2007) National BIM Standard Version 1 - Part 1: Overview, Principles, and Methodologies. National Institute for Building Sciences, Washington, DC. Available at: http://www.wbdg.org/pdfs/NBIMSv1_p1.pdf

Premkumar, G., Ramamurthy, K. (1995) The role of interorganizational and organizational factors on the decision mode for adoption of interorganizational systems, Decision Sciences, Vol. 26, Issue 3, 303-336

Succar, B. (2009) Building information modelling framework: A research and delivery foundation for industry stakeholders, Automation in Construction, Volume 18, Issue $3,357-375$

Söderstrom, E. (2004) Formulating a General Standards Life Cycle, In Proceedings of 16th International Conference of Advanced Information Systems Engineering - CaiSE 2004, LNCS 3084, Springer, Riga, Latvia (2004) 263-275.

Tekla press release 16.2.2009 - Tekla is first Finnish member of buildingSMART International. Available at: http://www.tekla.com/international/aboutus/news/pages/1290072_20090216070122.aspx Accessed on 22.02.2009

Tolman F, Böhms M, Lima C, van Rees R, Fleuren J and Stephens J (2001) eConstruct: expectations, solutions and results, ITcon Vol. 6, Special Issue Information and Communication Technology Advances in the European Construction Industry, 175-197, http://www.itcon.org/2001/13 